\title{
Use of heparin in neurointervention: a review of the literature
}

\author{
M. Zenteno ${ }^{1}$, L.R. Moscote-Salazar ${ }^{2}$, H. Alvis-Miranda ${ }^{3}$, A. Lee ${ }^{4}$ \\ ${ }^{1}$ Professor of Neurological Endovascular Therapy, Departamento de Terapia Endovascular \\ Neurológica, Instituto Nacional de Neurología y Neurocirugía, Universidad Nacional \\ Autónoma de México; StrokeUnit, Hospital Ángeles del Pedregal. \\ ${ }^{2}$ Department of Neurological Endovascular Therapy, Instituto Nacional de Neurología y \\ Neurocirugía; México City, México, mineurocirujano@aol.com \\ ${ }^{3}$ Universidad de Cartagena, Cartagena de Indias, Colombia \\ ${ }^{4}$ Department of Neurosurgery, Instituto Nacional de Ciencias Médicas y Nutrición Salvador \\ Zubirán; StrokeUnit, Hospital Ángeles del Pedregal, México City, México
}

\begin{abstract}
Background: The use of heparin is routine in endovascular procedures as a strategy in many centers that perform neurointerventional procedures to prevent occlusion of the catheters, but the use of this drug carries risks such as heparininduced thrombocytopenia.

Objective: The purpose of this paper is to present a review of the literature.

Material and methods: We conducted an extensive search and review of published papers about heparin and neurointerventional procedures.

Results: The evidence in the literature is weak in relation to the use of heparin and the reduction of embolic effects associated with their use in endovascular procedures.

Conclusion: The evidence on the use of heparin for the prevention of thromboembolic events in endovascular procedures are of low quality. There is insufficient evidence to conclude a potential benefit of heparin is useful in neurointerventional procedures. Prospective studies are needed to determine the effectiveness of heparin and avoid exposing patients to potential risks.
\end{abstract}

Key words: heparin, neurointervention, neuroangiography, arterial catheters.

\section{Introduction}

During neurointerventional procedures, the use of catheters is a key step in the realization of the same, many international centers have traditionally used heparin infusion in order to prevent the formation of clots inside the devices; this potential thrombus can migrate to different parts of the body and cause injury. Complications of angiography and endovascular procedures, whichhave historically been used for the diagnosis and treatment of neurovascular diseases, have rarely been described in the literature. The most frequent complication reported in the literature is bruising during these procedures. Complications derived from angiographic procedures such as anaphylaxis and death account for $0.03 \%$ and $0.06 \%$, respectively.

\section{Uses of heparin}

Heparin is the anticoagulant most frequently used in hospitalized patients in many neurosurgical centers. In 
industrialized nations, there are applied 80 million doses annually.

The use of heparin is directed to maintain the integrity of catheters used in endovascular therapy. Currently the use of low molecular weight heparins is to prevent venous thromboembolism. Heparin is a mucopolysaccharide acid with variable molecular weight (4.000 to $40.000 \mathrm{Da})$. Since 1935, high-molecular weightsheparins have been usedto inhibit platelet activityalso. Heparin acts in vitroas antithrombininhibitor, activating the plasma, which disables the thrombin and factor $\mathrm{Xa}$, then is metabolized byfast $\mathrm{N}$ desulfation after administration in the body. Usually heparin and similar products cause immunologically mediated thrombocytopenia, which usually occurs between the 5 th and the 10th day.

Usually the action of heparin is reversed by protamine sulfate, being the only agent that can stop heparin anticoagulation;complications of the use of protamine include systemic arterial hypotension, pulmonary arterial hypertension, bradycardia and oxygen consumption declination.

Kaufmann et al. evaluated and analyzed the complications of diagnostic angiographyin 19826 consecutive patients, in that work thrombotic events were only 9 $(0.05 \%)$. Neurological complications occurred within the first 24 hours of angiography in $2.63 \%$ of patients. (1)It has been reported the presentation of intracerebral hemorrhage associated to endovascular procedures in which heparin was used. (2) The vasodilatory effects of heparin have been reported due to rapid administration, in the form of boluses.

\section{Therapeutic uses}

Venous thromboembolism: Heparin have beenextensively used for prevention of venous thromboembolism, a fixed dose of heparin of 5000 IU subcutaneously administered, every 8 hours reduce from 60 to $70 \%$ the risk of venous thrombosis and decrease in mortality of $0.2 \%$ compared with control groups which evidenced a mortality of $0.7 \%$. (5).

Heparin has been used for many therapies along neurointervensionism evolution, such as aneurisms, (3, 4)atherothrombotic vertebrobasilar occlusion, (5) as part of the reperfusion strategies for acute ischemic stroke, (6-11) for free-floating carotid thrombus, (12) cerebral venous sinus thrombosis, $(9,13)$ primary stent revascularization, (14) among others.Heparin is recommended during interventions due to the use of multiple intravascular tools in procedures that can last several hours. (3) Currently, neurointerventional procedures are performed under therapeutic heparinization - even in cases of ruptured aneurysms - to prevent thromboembolic events. (15) Due to the fact that many published multicenter studies about the use of anticoagulants have left the doses to the judgment of the investigators, these had notbeen reported. However, doses reported by major monocenter studies (16-18) have been of initial boluses ranging from 3000 to 5000 IU followed by $20-40 \mathrm{IU} / \mathrm{kg} / \mathrm{h}$ continuously to maintain a monitored activated clotting time (ACT) between 200 and 300 seconds. (3) Protocols vary largely, and often comprise a standardized loading dose and no specified controls.

In other kind of endovascular procedures, after a baseline ACT is obtained, intravenous heparin (70 IU $/ \mathrm{kg}$ ) is 
generally given to a target prolongation of approximately 2 to 3 times the baseline value. Then heparin can be given continuously or as an intermittent bolus with hourly monitoring of ACT. (19)

Only $69 \%$ of the surveyed members of The World Federation of Interventional and Therapeutic Neuroradiology (WFITN), uses heparin intraoperatively and in a continuous fashion. (3) The WFITN recommends a 5000 IU bolus, then $1000 \mathrm{IU} / \mathrm{h}$ continuously, with (monitored) ACT at about 200s. Nevertheless, there are many recommendations for heparin use outside the field of interventional neuroradiology that may be adaptable to the endovascular treatment of aneurisms. (20) The normally employed monitoring method is ACT, with guideline values $>200 \mathrm{~s}$, most commonly between 250 and 300 seconds. (21)

It is recommended to test the efficacy of the heparin regularly during the intervention. Loading and continuous doses must be adapted to the patient's weight to rapidly attain and maintain ACT objectives during the intervention, which may take several hours (3).

Preoperative oral anticoagulants are usually stopped 5 days before the intervention and replaced by heparin, which has the advantage of being easily antagonized in cases of intraoperative aneurism rupture. (3) Protamine sulfate dose for dose in the last hour will rapidly terminate heparinization. Some teams continue heparin infusion for $24-48 \mathrm{~h}$, but the WFITN does not recommend pursuing anticoagulation postoperatively. (3)

Any rationale for postoperative use of heparin is unclear. Indeed, no convincing clinical results have been published, and from a biological perspective it seems more pertinent to use antiplatelets. (3) On the other hand, there is insufficient evidence to support the use of either systemic or local thrombolysis in patients who have cerebral sinus venous thrombosis (CVST) according to European Federation of Neurologic Societies guidelines.

Heparin use must be monitored. The effect of the heparin lasts for at least a few hours and patients usually need to be placed on antiplatelet therapy after the procedure.

In the resuscitation phase of any intracranial catastrophe, when the patient is receiving heparin, the presence of hemorrhage should elicit immediate heparin reversal $(1 \mathrm{mg}$ protamine for each 100 units of heparin given) and low normal mean arterial pressure. (19)

There are reports regard the use of heparin as an adjunct to neurointerventional procedures that can result in rapidly progressive intracerebral hemorrhages; (2) abciximab, aspirin, thienopyridinederivates are also reported. Careful management of coagulation is required to prevent thromboembolic complications during and after the neurointerventional procedure. (19)

When a patient may be refractory to attempts to obtain adequate anticoagulation, (19) should be considered the switching from bovine to porcine heparin or vice versa. If antithrombin III deficiency is suspected, administration of fresh frozen plasma may be necessary to allow heparin to have its desired anticoagulant effect. (19)

Thrombolytic therapy with recombinant tissue plasminogen activator (rt-PA) and secondary anticoagulation with heparin to prevent rethrombosis in acute stroke patients has been shown to be beneficial in large randomized trials, (22) but the major 
complication of this therapy is secondary postischemic symptomatic intracranial hemorrhage (SICH), (23) which can be devastating. It is necessary to detect microbleeds (MBs) or hemorrhagic transformation (HT) early and accurately, and to institute rapid treatment decisionmaking according to neuroimaging findings to prevent development of a hemorrhageprone state and improve neurologic recovery. (24-26)

Other complications derived from the use of heparin, is the heparin-related $\mathrm{ICH}$, which is rare and data are sparse regarding appropriate treatment. One reasonable approach would be to reverse heparin with IV protamine sulfate at a dose of $1 \mathrm{mg}$ to 1.5 $\mathrm{mg}$ per 100 units of heparin with a maximum dose of $50 \mathrm{mg}$. $(27,28)$

Heparin-induced thrombocytopenia (HIT) is a rare but important adverse event for heparin anticoagulation. (19)The incidence of HIT in neurological patients continues to increase with expansion of indication for neurointerventional procedures. The pathophysiology of HIT is related to a hypersensitivity reaction against complex platelet factor 4. (29) The diagnosis is mostly clinical and is often confirmed by laboratory testing. (29) Patients with HIT have a higher rate of thromboembolic complications, both arterial and venous, and with worse neurological outcomes at the time of discharge. Early diagnosis and heparin cessation are essential in the management of those patients. Both immediate and prolonged alternative anticoagulation are necessary. Understanding of the mechanism of action, indication and drug interaction of the alternative anticoagulants (direct thrombin inhibitors, fondaparinux and danaparoid) and warfarin is essential during management of these patients. (29)

Often, the thromboembolic risks in the endovascular treatment of aneurisms are lesser than those found in stenting or extracranial angioplasty (3).

\section{Conclusion}

Clearly, heparin is not an innocuous molecule; indications for its use should be clearly stated in individualized patients, assessing factors such as comorbidities, age, allergic states, time for use, and clinical evolution. However heparin may be useful only in cases where the patient has prothrombotic states. As stated previously, clinical studies had lead dosage to author's criteria, thus there is not a widely assessed dosage for heparin, especially in patients with neurovascular conditions. It is needed more unification for indication, dosage and cessation criteria. Prospective studies are needed to determine the effectiveness of heparin and avoid exposing patients to potential risks.

\section{Disclosure}

The authors have no personal financial or institutional interest in any of the drugs, materials or device describe in this article.

\section{Corresponding author:}

Marco Zenteno, MD

Instituto Nacional de Neurologia y Neurocirurgia "Manuel Velasco Suarez"; 3877, México City, México;mazente@me.com, dr_angel_lee@yahoo.de

\section{References}

1. Kaufmann TJ, Huston J, Mandrekar JN, Schleck CD, Thielen KR, Kallmes DF. Complications of diagnostic cerebral angiography: evaluation of 19,826 consecutive patients. Radiology 2007;243:812-9. 
2. Qureshi AI, Saad M, Zaidat OO, Suarez JI, Alexander MJ, Fareed M, Suri K, Ali Z, Hopkins LN. Intracerebral hemorrhages associated with neurointerventional procedures using a combination of antithrombotic agents including abciximab. Stroke 2002;33:1916-9.

3. Bracard S, Barbier C, Derelle AL, Anxionnat R. Endovascular treatment of aneurisms: Pre, intra and post operative management. European Journal of Radiology n.d.

4. Gao X, Liang G, Li Z, Wei X, Cao P. A single-centre experience and follow-up of patients with endovascular coiling of large and giant intracranial aneurysms with parent artery preservation. Journal of Clinical Neuroscience 2012;19:364-9.

5. Cohen JE, Gomori JM, Itshayek E, Leker RR. Adjuvant use of self-expanding stents in acute atherothrombotic vertebrobasilar occlusions. Journal of Clinical Neuroscience 2013;20:597-601.

6. Cohen JE, Itshayek E, Moskovici S, Gomori JM, Fraifeld S, Eichel R, Leker RR. State-of-the-art reperfusion strategies for acute ischemic stroke. Journal of Clinical Neuroscience 2011;18:319-23.

7. Cruz Culebras A, García-Pastor A, Reig G, Fuentes B, Simal P, Méndez-Cendón JC, Caniego JL, Castro E, Frutos R, Gil A, Vivancos J, Gil-Núñez A, DíezTejedor E, Egido JA, Alonso de Leciñana M, Masjuan J. Neurovascular intervention in the acute phase of cerebral infarction. Neurología (English Edition) 2010;25:279-86.

8. Dabus G, Linfante I. The Natural History of Acute Ischemic Stroke Due to Intracranial Large-Vessel Occlusion: What Do We Know? Techniques in Vascular and Interventional Radiology 2012;15:2-4.

9. Perry JM, McCabe KK. Recognition and Initial Management of Acute Ischemic Stroke. Emergency Medicine Clinics of North America 2012;30:637-57.

10. Singh J, Nguyen TN. Endovascular and Neurosurgical Management of Acute Ischemic Stroke. Emergency Medicine Clinics of North America 2012;30:695-712.

11. Titomanlio L, Zanin A, Sachs P, Khaled J, Elmaleh M, Blanc R, Piotin M. Pediatric Ischemic Stroke: Acute Management and Areas of Research. The Journal of Pediatrics 2013;162:227-235.e1.

12. Elijovich L, Mainali S, Doss V, Arthur A, Watridge C. Medical management of free-floating carotid thrombus. Clinical Neurology and Neurosurgery n.d. 13. Guo X-B, Fu Z, Song L-J, Guan S. Local thrombolysis for patients of severe cerebral venous sinus thrombosis during puerperium. Eur J Radiol 2013;82:165-8

14. Gordhan A, Castillo R, Reino W, Jani J. Primary stent revascularization for critical flow-limiting middle cerebral artery stenosis presenting with rapid neurologic decline. Am J Emerg Med 2011;29:963.e5-8.

15. Jahshan S, Hopkins III LN. If You Want to Learn New Things, Read Old Books: Cutdown Techniques Are Well Described in the Old Literature. World Neurosurgery 2012;77:83-4.

16. Park H-K, Horowitz M, Jungreis C, Genevro J, Koebbe C, Levy E, Kassam A. Periprocedural morbidity and mortality associated with endovascular treatment of intracranial aneurysms. AJNR Am J Neuroradiol 2005;26:506-14.

17. Qureshi AI, Luft AR, Sharma M, Guterman LR, Hopkins LN. Prevention and treatment of thromboembolic and ischemic complications associated with endovascular procedures: Part I-Pathophysiological and pharmacological features. Neurosurgery 2000;46:1344-59.

18. Hussein HM, Georgiadis AL, Qureshi AI. Pointof-care testing for anticoagulation monitoring in neuroendovascular procedures. AJNR Am J Neuroradiol 2012;33:1211-20.

19. Lee CZ, Young WL. Anesthesia for Endovascular Neurosurgery and Interventional Neuroradiology. Anesthesiology Clinics 2012;30:127-47.

20. Hirsh J, Anand SS, Halperin JL, Fuster V. Guide to anticoagulant therapy: Heparin : a statement for healthcare professionals from the American Heart Association. Circulation 2001;103:2994-3018.

21. Brott TG, Halperin JL, Abbara S, Bacharach JM, Barr JD, Bush RL, Cates CU, Creager MA, Fowler SB, Friday G, Hertzberg VS, McIff EB, Moore WS, Panagos PD, Riles TS, Rosenwasser RH, Taylor AJ. 2011 ASA/ACCF/AHA/AANN/AANS/ACR/ASNR/CNS/SA IP/SCAI/SIR/SNIS/SVM/SVS Guideline on the Management of Patients With Extracranial Carotid and Vertebral Artery Disease: A Report of the American College of Cardiology Foundation/American Heart Association Task F. Journal of the American College of Cardiology 2011;57:e16-e94.

22. Hacke W, Donnan G, Fieschi C, Kaste M, Von Kummer R, Broderick JP, Brott T, Frankel M, Grotta JC, Haley EC, Kwiatkowski T, Levine SR, Lewandowski C, Lu M, Lyden P, Marler JR, Patel S, Tilley BC, Albers G, Bluhmki E, Wilhelm M, Hamilton S. Association of outcome with early stroke treatment: pooled analysis of ATLANTIS, ECASS, and NINDS rt-PA stroke trials. Lancet 2004;363:768-74.

23. Intracerebral hemorrhage after intravenous tPA therapy for ischemic stroke. The NINDS t-PA Stroke Study Group. Stroke 1997;28:2109-18.

24. Hjort N, Butcher K, Davis SM, Kidwell CS, Koroshetz WJ, Röther J, Schellinger PD, Warach S, Østergaard L. Magnetic resonance imaging criteria for thrombolysis in acute cerebral infarct. Stroke 2005;36:388-97.

25. Kang D-W, Chalela JA, Dunn W, Warach S. MRI 
screening before standard tissue plasminogen activator therapy is feasible and safe. Stroke 2005;36:1939-43.

26. Kidwell CS, Saver JL, Villablanca JP, Duckwiler G, Fredieu A, Gough K, Leary MC, Starkman S, Gobin YP, Jahan R, Vespa P, Liebeskind DS, Alger JR, Vinuela F. Magnetic resonance imaging detection of microbleeds before thrombolysis: an emerging application. Stroke 2002;33:95-8.

27. Gurol ME, Greenberg SM. Management of intracerebral hemorrhage. Curr Atheroscler Rep 2008;10:324-31.

28. Caceres JA, Goldstein JN. Intracranial Hemorrhage. Emergency Medicine Clinics of North America 2012;30:771-94.

29. Alaraj A, Wallace A, Tesoro E, Ruland S, AminHanjani S, Charbel FT, Aletich V. Heparin induced thrombocytopenia: diagnosis and management. J Neurointerv Surg 2010;2:371-8. 